\title{
Metabolic and hormonal changes during and after exchange transfusion with heparinized or ACD blood
}

\author{
AGNES CSER and R. D. G. MILNER \\ From the Department of Child Health, University of Manchester
}

\begin{abstract}
Cser, A., and Milner, R. D. G. (1974). Archives of Disease in Childhood, 49, 940. Metabolic and hormonal changes during and after exchange transfusion with heparinized or ACD blood. Plasma glucose, free fatty acid (FFA), insulin, and growth hormone concentrations were measured during and for 3 hours after exchange transfusion in two comparable groups of newborn infants suffering from jaundice due to haemolytic disease, infection, or prematurity. 10 transfusions were performed using blood preserved with acid citrate and dextrose (ACD) and in these there was a doubling of plasma glucose and a fourfold rise in plasma insulin. Plasma FFA fell in ACD transfusions but doubled during 9 transfusions in which heparinized blood was used. Plasma glucose and insulin remained unchanged in heparin transfusions and no significant change in plasma growth hormone occurred during or after either type of transfusion.

After the transfusion plasma glucose fell rapidly in the ACD group, but despite the falling plasma glucose concentration plasma insulin levels rose further and did not begin to fall until 60 minutes after transfusion. Plasma FFA remained steady for one hour and then rose to twice the pretransfusion level at 3 hours. In the heparin group plasma FFA remained high and did not change significantly in the 3-hour posttransfusion period, whereas plasma glucose and insulin remained at pretransfusion levels throughout.

Infants transfused with ACD blood are at risk from post-transfusion hypoglycaemia, whereas those given heparinized blood are at risk from a greater rebound rise in unbound unconjugated bilirubin. Both risks may be reduced by feeding the infant as soon as is practicable.
\end{abstract}

Exchange transfusions are usually performed using fresh blood preserved with acid citrate and dextrose (ACD) because this method of blood preservation is the most convenient and practical for the haematologist and paediatrician to employ. Farquhar and Smith (1958) were the first to investigate the effects of the blood preservative on the recipient of an exchange transfusion and more recent work has documented such changes as a fall in plasma ionized calcium (Radde et al., 1972), an acute acidosis followed by a late alkalosis (Calladine $e t$ al., 1965), and post-transfusion hypoglycaemia (Schiff $e t$ al., 1971b). Heparin has been used as an anticoagulant since the introduction of exchange transfusion for neonatal jaundice (Wiener and Wexler, 1946) and early published reports contain a

Received 22 May 1974. number of communications which commend the use of heparinized blood (see Bentley, Ziegler, and Krivit, 1960). Despite the early study of competition between bilirubin and other anions for binding by albumin (Odell, 1959) and the demonstration that FFA could displace bilirubin from albumin (Polacek, Novak, and Melichar, 1965), it was not until 1971 that Schiff and his colleagues showed that the stimulation of plasma FFA levels during exchange transfusion with heparinized blood caused a reduced albumin binding capacity for bilirubin. The stimulation of lipolysis by heparin due to activation of lipoprotein lipase (see Ehrlich and Stivala, 1973) is a side effect in exchange transfusion but one which may cause iatrogenic damage.

The present study was performed to investigate the effects of exchange transfusion with ACD or 
TABLE I

Clinical details of infants and exchange transfusions

\begin{tabular}{|c|c|c|c|c|c|c|c|}
\hline \multirow{2}{*}{$\begin{array}{c}\text { Clinical group and } \\
\text { no. of } \\
\text { transfusions }\end{array}$} & \multicolumn{2}{|c|}{$\begin{array}{l}\text { No. of } \\
\text { patients } \\
\text { and sex }\end{array}$} & \multicolumn{5}{|c|}{ Mean (range) } \\
\hline & $\mathbf{M}$ & F & $\begin{array}{c}\text { Gestational } \\
\text { age } \\
\text { (wk) }\end{array}$ & $\begin{array}{l}\text { Birthweight } \\
\quad(\mathrm{kg})\end{array}$ & $\begin{array}{c}\text { Postnatal age } \\
\text { (hr) }\end{array}$ & $\begin{array}{l}\text { Time from } \\
\text { last meal } \\
(\mathrm{min})\end{array}$ & $\begin{array}{c}\text { Volume } \\
\text { transfused/blood } \\
\text { vol of infant }\end{array}$ \\
\hline $\begin{array}{l}\text { ACD blood (10) } \\
\text { Heparin blood (9) }\end{array}$ & $\begin{array}{l}5 \\
5\end{array}$ & $\begin{array}{l}4 \\
3\end{array}$ & $\begin{array}{l}35 \cdot 8(32-41) \\
36 \cdot 9(35-40)\end{array}$ & $\begin{array}{l}2 \cdot 53(1 \cdot 70-3 \cdot 14) \\
2 \cdot 78(2 \cdot 12-3 \cdot 66)\end{array}$ & $\begin{array}{l}52(2-95) \\
59(9-137)\end{array}$ & $\begin{array}{l}114(0-240) \\
152(20-240)\end{array}$ & $\begin{array}{l}2 \cdot 19(1 \cdot 59-3 \cdot 00) \\
2 \cdot 24(1 \cdot 93-2 \cdot 42)\end{array}$ \\
\hline
\end{tabular}

heparinized blood on the infant particularly in the post-transfusion period. Previous studies had described the effects of ACD blood on the infant during exchange transfusion (Milner et al., 1972b; Milner, Fekete, and Assan, 1972a), but these measurements had to be repeated since it was not certain that rinsing solutions in the earlier work had always been free of heparin. The post-transfusion period was of special interest as this is the time when the infant is at risk from hypoglycaemia or rebound hyperbilirubinaemia.

\section{Patients and methods}

Nineteen exchange transfusions were performed for hyperbilirubinaemia in infants whose clinical details are summarized in Table I. All transfusions were carried out via the umbilical vein as described previously (Milner et al., 1972b); in 10 the blood was preserved with $\mathrm{ACD}$ and in 9 with heparin. The mean plasma glucose of the ACD blood was $515 \mathrm{mg} / 100 \mathrm{ml}$, whereas that of the heparin blood was $77 \mathrm{mg} / 100 \mathrm{ml}$ (Table II). The infants were not rigorously selected for gestational age and though both groups contained preterm infants, all were of normal birthweight for gestational age. One infant in each group was studied twice. In each group 3 infants were transfused because of hyperbilirubinaemia due to prematurity, one in each group because of jaundice complicating infection, and the remainder were jaundiced due to haemolytic disease.

Care was taken to avoid the injection of fluid containing heparin into any infants before, during, or after the transfusion excepting the blood anticoagulated with heparin. At the end of the transfusion the umbilical venous catheter was left in place and blood samples were collected at intervals for 3 hours, leaving the infant at the end of this time in the desired haemodynamic balance. Between sample collections the dead space of the catheter was filled with normal saline. Blood samples were collected and stored as described previously and the haematocrit and plasma concentrations of glucose, FFA, insulin, and growth hormone were measured (Milner et al., 1972b).

\section{Results}

The two groups of infants were similar clinically and of the four substances measured significant differences were noted only in the mean donor plasma insulin and infants' plasma FFA, which were lower in the ACD group $(P<0 \cdot 05)$. These differences were considered to be unlikely to

TABLE II

Plasma metabolite and hormone concentrations $( \pm S E)$ in infants having exchange transfusions with blood preserved with $A C D$ or heparin

\begin{tabular}{|c|c|c|c|c|c|c|}
\hline & Donor & $0 \mathrm{ml}$ & $100 \mathrm{ml}$ & $200 \mathrm{ml}$ & $300 \mathrm{ml}$ & $400 \mathrm{ml}$ \\
\hline $\begin{array}{l}A C D \\
\text { Glucose }(\mathrm{mg} / 100 \mathrm{ml}) \\
\text { FFA }(\mu \mathrm{mol} / 1 .) \\
\text { Insulin }(\mu \mathrm{U} / \mathrm{ml}) \\
\text { Growth hormone }(\mathrm{ng} / \mathrm{ml})\end{array}$ & $\begin{array}{c}515 \pm 19(10) \\
407 \pm 68(10) \\
14 \pm 3(10)^{\star} \\
1 \cdot 7 \pm 0 \cdot 7(10)\end{array}$ & $\begin{array}{c}79 \pm 10(10) \\
782 \pm 86(10) \star \\
17 \pm 3(10) \\
35 \pm 5(10)\end{array}$ & $\begin{array}{l}135 \pm 8(10) \ddagger \\
733 \pm 104(10) \ddagger \\
31 \pm 6(10) \\
34 \pm 6(10)\end{array}$ & $\begin{array}{c}155 \pm 11(10) \ddagger \\
628 \pm 70(10) \ddagger \\
50 \pm 7(10) \\
33 \pm 6(10)\end{array}$ & $\begin{array}{c}166 \pm 10(10) \ddagger \\
617 \pm 60(10) \ddagger \\
63 \pm 12(10) \dagger \\
37 \pm 5(10)^{\star}\end{array}$ & $\begin{array}{c}176 \pm 11(10) \ddagger \\
578 \pm 71(10) \ddagger \\
78 \pm 16(10) \dagger \\
40 \pm 5(10) \dagger\end{array}$ \\
\hline $\begin{array}{l}\text { Heparin } \\
\text { Glucose }(\mathrm{mg} / 100 \mathrm{ml}) \\
\text { FFA }(\mu \mathrm{mol} / 1 .) \\
\text { Insulin }(\mu \mathrm{U} / \mathrm{ml}) \\
\text { Growth hormone }(\mathrm{ng} / \mathrm{ml})\end{array}$ & $\begin{array}{c}77 \pm 7(9) \\
604 \pm 150(9) \\
33 \pm 8(9) \\
2 \cdot 0 \pm 0 \cdot 4(9)\end{array}$ & $\begin{array}{c}75 \pm 5(9) \\
1272 \pm 198(9) \\
15 \pm 3(9) \\
40 \pm 10(9)\end{array}$ & $\begin{array}{c}78 \pm 6(9) \\
2147 \pm 197(9) \\
18 \pm 4(9) \\
25 \pm 4(9)\end{array}$ & $\begin{aligned} 74 & \pm 8(9) \\
2290 & \pm 213(9) \\
17 & \pm 2(9) \\
19 & \pm 3(9)\end{aligned}$ & $\begin{array}{c}74 \pm 7(9) \\
2429 \pm 265(9) \\
25 \pm 5(9) \\
23 \pm 4(9)\end{array}$ & $\begin{array}{c}75 \pm 8(7) \\
2249 \pm 343(7) \\
21 \pm 2(7) \\
20 \pm 3(8)\end{array}$ \\
\hline
\end{tabular}

Level of statistical significance for comparison with infants transfused with heparinized blood: ${ }^{P}<0.05,+P<0 \cdot 01, \ddagger P<0 \cdot 001$. Number of observations is shown in parentheses. 
Plasma metabolite and hormone concentrations $( \pm S E)$ in infant:

\begin{tabular}{|c|c|c|c|}
\hline & $5 \mathrm{~min}$ & $10 \mathrm{~min}$ & $20 \mathrm{~min}$ 읃 \\
\hline $\begin{array}{l}A C D \\
\text { Glucose }(\mathrm{mg} / 100 \mathrm{ml}) \\
\text { FFA }(\mu \mathrm{mol} / 1 .) \\
\text { Insulin }(\mu \mathrm{U} / \mathrm{ml}) \\
\text { Growth hormone }(\mathrm{ng} / \mathrm{ml})\end{array}$ & $\begin{aligned} 154 & \pm 12(10) \ddagger \\
757 & \pm 130(10) \ddagger \\
109 & \pm 26(10) \dagger \\
36 & \pm 6(10)\end{aligned}$ & $\begin{aligned} 131 & \pm 11(10) \ddagger \\
748 & \pm 98(10) \ddagger \\
122 & \pm 28(10) \dagger \\
34 & \pm 5(10)\end{aligned}$ & $\begin{array}{l}116 \pm 9(10) \\
804 \pm 89 \text { (19)* } \\
118 \pm 22(18) \neq \\
30 \pm 5(18)\end{array}$ \\
\hline $\begin{array}{l}\text { Heparin } \\
\text { Glucose }(\mathrm{mg} / 100 \mathrm{ml}) \\
\text { FFA }(\mu \mathrm{mol} / 1 .) \\
\text { Insulin }(\mu \mathrm{U} / \mathrm{ml}) \\
\text { Growth hormone }(\mathrm{ng} / \mathrm{ml})\end{array}$ & $\begin{aligned} 79 & \pm 9(8) \\
2083 & \pm 270(8) \\
23 & \pm 4(8) \\
21 & \pm 4(8)\end{aligned}$ & $\begin{array}{c}75 \pm 9(9) \\
2303 \pm 272(9) \\
20 \pm 4(9) \\
23 \pm 4(9)\end{array}$ & 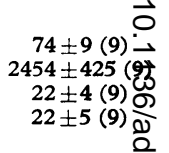 \\
\hline
\end{tabular}

Level of statistical significance for comparison with infants transfused with heparinized blood: ${ }^{\star} P<0 \cdot 05,+P \dot{q 0} \cdot 01$

Number of observations is shown in parentheses.

influence the changes produced by the glucose in the ACD transfusions and by the heparin-stimulated lipolysis in the heparin group. The plasma concentrations of hormones and metabolites are reported as mean values in Tables II and III and as mean changes from the value at the start of transfusion or the value 5 minutes after transfusion in the Fig.

During transfusion. Transfusion with ACD blood caused a progressive rise in mean plasma glucose concentration which tended to a plateau at the end of the procedure (Table II, Fig.). The associated rise in mean plasma insulin and fall in mean plasma FFA was significant from the $200 \mathrm{ml}$ point onwards $(P<0.05)$. The infants transfused with heparinized blood were characterized by a sharp and large rise in mean plasma FFA which doubled by the $100 \mathrm{ml}$ sample and then remained steady. Despite the mean donor plasma insulin concentration being twice that in the infant at the start, there was no significant change during transfusion with the exception of the $300 \mathrm{ml}$ sample $(\mathbf{P}<0 \cdot 05)$. Plasma growth hormone levels did not change significantly in either group. During the transfusions the glucose and insulin levels were significantly higher in the ACD group and the FFA levels were higher in the heparin group.

After transfusion. Plasma glucose levels in the ACD group fell after the transfusion. The rate of glucose disappearance for each infant $\left(K_{t}\right)$ was calculated as described by Greville (1943) and the mean result was $1 \cdot 65 \%$ /minute (range $1 \cdot 08-2 \cdot 82$ ). The glucose levels continued to drop in the second and third hours, reaching a minimum mean value of $33 \mathrm{mg} / 100 \mathrm{ml}$ at 180 minutes (Table III). In individual babies the minimum plasma glucose occurred equally at 120 or 180 minutes, but never at 60 minutes. The 60 -minute plasma glucose level correlated linearly with the $K_{t}$ value $(P<0.001)$, but neither was any guide to the glucose level at 120 or 180 minutes or to the minimum plasma glucose. Asymptomatic hypoglycaemia occurred in 3 infants who had plasma glucose levels of 15,16 , and 12 $\mathrm{mg} / 100 \mathrm{ml}$. In infants receiving heparinized blood there was no significant change in plasma glucose at any time (Fig.) and the lowest plasma glucose concentration measured was $42 \mathrm{mg} / 100 \mathrm{ml}$.

Mean plasma FFA levels rose by half in the ACD group 5 minutes after the transfusion, but the concentration then remained steady for 35 minutes. From 40 to 180 minutes there was a progressive rise in plasma FFA but due to large individual variations this difference was significant from that at 5 minutes only at 180 minutes $(P<0.01)$ (Fig.). No significant change in plasma FFA levels occurred in the heparin group after transfusion (Fig.), the mean value remaining raised up to 180 minutes.

After transfusion in the ACD group, there was a sharp rise in mean plasma insulin levels which remained high for 40 minutes. From 40 to 180 minutes there was a progressive fall in mean values, but wide variation between infants, as seen by the standard errors in the Fig., meant that only the 120and 180-minute changes were significantly less than the value at 5 minutes $(P<0 \cdot 05)$. No significant change in plasma insulin occurred after transfusion in the heparin group and at 180 minutes the mean value was the same as that at the start of transfusion, but half that in the ACD group at this time.

No significant change occurred after transfusion in plasma growth hormone levels in either group with the exception of the 180-minute level in the ACD group which was lower than that at 5 minutes $(P<0 \cdot 01)$. Up to 120 minutes the mean growth hormone levels in the heparin group tended to be 
xfter exchange transfusion with blood preserved with ACD or heparin

\begin{tabular}{c|c|c|c|c}
\hline $30 \mathrm{~min}$ & $40 \mathrm{~min}$ & $60 \mathrm{~min}$ & $120 \mathrm{~min}$ & $180 \mathrm{~min}$ \\
\cline { 2 - 4 } & & & & \\
$101 \pm 9(10)^{\star}$ & $89 \pm 9(10)$ & $66 \pm 7(10)$ & $37 \pm 5(9) \ddagger$ & $33 \pm 5(8) \dagger$ \\
$864 \pm 136(10) \dagger$ & $792 \pm 133(10) \dagger$ & $950 \pm 161(10) \dagger$ & $1126 \pm 150(9)^{\star}$ & $1630 \pm 156(8)$ \\
$131 \pm 27(10) \ddagger$ & $123 \pm 26(10) \dagger$ & $69 \pm 17(10) \dagger$ & $41 \pm 10(10)^{\star}$ & $33 \pm 11(9)$ \\
$34 \pm 5(10)$ & $36 \pm 7(10)$ & $47 \pm 12(10)$ & $36 \pm 12(9)$ & $17 \pm 4(8)$ \\
& & & & \\
$73 \pm 9(9)$ & $73 \pm 9(9)$ & $74 \pm 8(8)$ & $67 \pm 6(7)$ & $61 \pm 7(7)$ \\
$222 \pm 370(9)$ & $2057 \pm 360(9)$ & $2126 \pm 288(8)$ & $1900 \pm 266(7)$ & $1836 \pm 298(7)$ \\
$20 \pm 3(9)$ & $24 \pm 5(9)$ & $19 \pm 4(8)$ & $17 \pm 3(7)$ & $16 \pm 2(7)$ \\
$24 \pm 7(9)$ & $27 \pm 9(9)$ & $28 \pm 7(8)$ & $26 \pm 9(7)$ & $24 \pm 5(7)$ \\
& & & & \\
\hline
\end{tabular}

$P<0 \cdot 001$.

lower, but not significantly so, than those in the heparin group.

Net balances. The different metabolic effects of the two types of transfusion were clearly illustrated in the calculations of total amounts of metabolite and hormone infused and removed from the infants (Table IV). ACD transfusions caused a large net positive balance of glucose accompanied by a negative balance of insulin, whereas heparin transfusions resulted in 6 times as much FFA being washed out of the infants as occurred in ACD transfusions. The negative growth hormone balance of the ACD transfusions was not significantly greater than that in the heparin transfusions.

\section{Discussion}

The salient findings in the present study are the post-transfusion hypoglycaemia in infants given
ACD blood and the prolonged effect of heparin on plasma FFA levels in infants transfused with heparinized blood. These results confirm and extend the work of Schiff et al. (1971a, b).

Earlier work has shown a close linear correlation between glucose disappearance and the 60-minute post-transfusion plasma glucose level (Milner, Chouksey, and Assan, 1973), suggesting that the latter might be a prognostic guide to the infants likely to become hypoglycaemic. Neither the present results nor those from transfusions performed via the umbilical artery (Cser and Milner, 1975) confirm this idea, but indicate rather that glucose homoeostasis in the second and third hours after transfusion is not closely related to the way in which the glucose load is handled in the first hour. Similar results in infants of diabetic mothers given a bolus injection of glucose were observed by Isles, Dickson, and Farquhar (1968). The glucose

TABLE IV

Amounts $( \pm S E)$ of metabolites and hormones infused and removed during exchange transfusion with ACD or heparin blood

\begin{tabular}{|c|c|c|c|}
\hline \multirow{2}{*}{ Metabolite or hormone } & \multicolumn{3}{|c|}{ Amount infused or removed/kg body weight (mean $\pm \mathrm{SE}$ ) } \\
\hline & In & Out & Balance \\
\hline $\begin{array}{l}\text { ACD blood (10) } \\
\text { Glucose (mg) } \\
\text { FFA ( } \mu \mathrm{mol}) \\
\text { Insulin (mU) } \\
\text { Growth hormone }(\mu \mathrm{g})\end{array}$ & $\begin{array}{l}427 \pm 37 \dagger \\
31 \cdot 0 \pm 4 \cdot 9 \\
1 \cdot 26 \pm 0 \cdot 31^{\star} \\
0 \cdot 15 \pm 0 \cdot 06\end{array}$ & $\begin{array}{l}135 \pm 13^{\star} \\
58 \cdot 5 \pm 4 \cdot 6 \dagger \\
4 \cdot 48 \pm 0 \cdot 54 \dagger \\
3 \cdot 25 \pm 0 \cdot 47\end{array}$ & $\begin{array}{l}+292 \pm 31 \dagger \\
-27 \cdot 5 \pm 4 \cdot 2 \dagger \\
-3 \cdot 22 \pm 0 \cdot 81 \dagger \\
-3 \cdot 09 \pm 0.51\end{array}$ \\
\hline $\begin{array}{l}\text { Heparin blood }(9) \\
\text { Glucose }(\mathrm{mg}) \\
\text { FFA ( } \mu \mathrm{mol}) \\
\text { Insulin (mU) } \\
\text { Growth hormone }(\mu \mathrm{g})\end{array}$ & $\begin{array}{c}78 \pm 7 \\
59 \cdot 4 \pm 15 \cdot 7 \\
2 \cdot 67 \pm 0 \cdot 40 \\
0 \cdot 19 \pm 0 \cdot 04\end{array}$ & $\begin{aligned} 77 & \pm 8 \\
230 \cdot 7 & \pm 30 \cdot 3 \\
2 \cdot 09 & \pm 0 \cdot 21 \\
2 \cdot 36 & \pm 0 \cdot 32\end{aligned}$ & $\begin{array}{c}+1 \pm 1 \\
-171 \cdot 3 \pm 24 \cdot 0 \\
+0.58 \pm 0 \cdot 38 \\
-2 \cdot 17 \pm 0.33\end{array}$ \\
\hline
\end{tabular}

Levels of significance for comparison with infants transfused with heparinized blood: $\star P<0 \cdot 01,+P<0 \cdot 001$.

Number of observations shown in parentheses. 

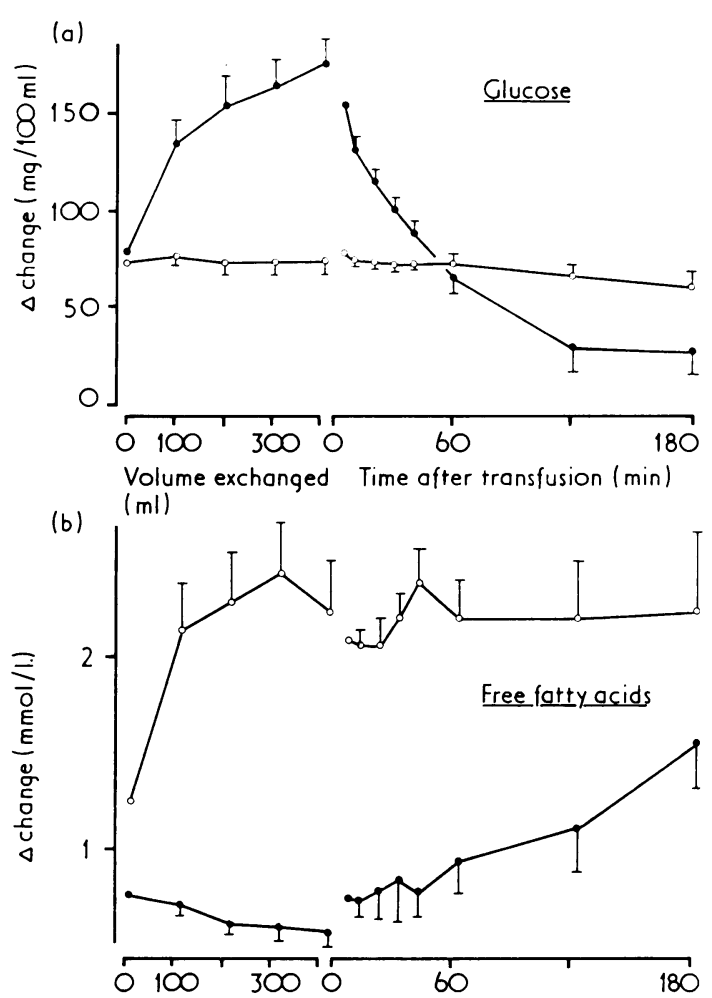

Volume exchanged Time after transfusion ( $\mathrm{min}$ )

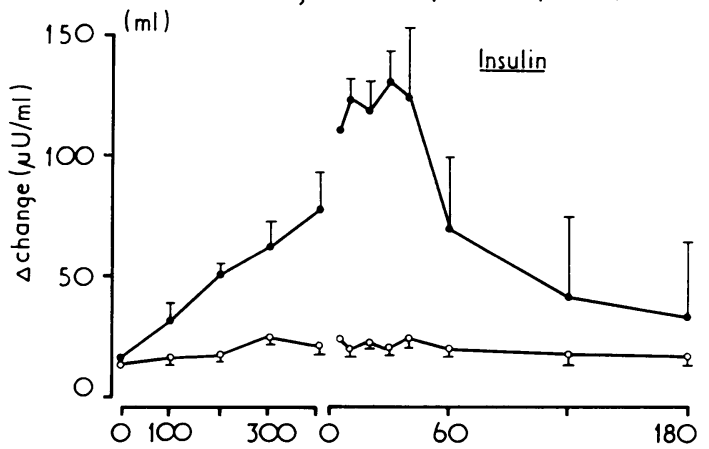

(c) Volume exchanged Time after transfusion ( $\mathrm{min}$ ) ( $\mathrm{ml}$ )

FIG.-Mean ( $\pm S E$ ) change in (a) plasma glucose, (b) free fatty acid, and (c) insulin concentration from the level at the start of exchange transfusion or 5 minutes after the transfusion ended. ACD transfusions O, heparin transfusions $\bigcirc$.

disappearance rates reported here are similar to those of erythroblastotic infants given an acute intravenous glucose injection (Falorni et al., 1972; Mølsted-Pedersen, Trautner, and Jørgensen, 1973). This illustrates the complicated relation between glucose disappearance and insulin secretion, as the plasma insulin levels were high throughout the period of measurement after exchange transfusion, but only rose from basal levels 30 minutes after glucose injection.

As noted before (Schiff et al., 1971b; Milner et al., 1972a, b, 1973), there was considerable variation in plasma insulin levels between infants. A catheter tip in the porta hepatis sampling pancreatic effluent results in higher plasma insulin levels than if it were in the inferior vena cava sampling mixed venous blood. Though this is probably the explanation of the variation of the insulin values in the ACD group, it could not explain the differences between the $A C D$ and heparin groups. Increased insulin secretion occurred in all the infants receiving ACD blood and was responsible for the low mean plasma glucose levels at 2 and 3 hours post-transfusion, but no infant in the heparin group responded to transfusion with a clear rise in plasma insulin. The clinical impracticability of monitoring the catheter position weakens the use of transfusions performed via the umbilical vein as a research tool, but has no implication for the patient with regard to posttransfusion hypoglycaemia which was not related to plasma insulin levels. Lower and more homogeneous plasma insulin levels and less hypoglycaemia were recorded in transfusions performed via the umbilical artery (Cser and Milner, 1975).

Plasma ionized calcium concentrations return to normal after exchange transfusion in 30 minutes (Farquhar and Smith, 1958; Radde et al., 1972), suggesting that little citrate anticoagulant effect persists thereafter. Little is known about the metabolism and biological half-life of heparin in the newborn, but infants exchange transfused with heparinized blood do have a prolonged clotting and prothrombin time at the end of the transfusion which is correctable by intramuscular protamine sulphate injection (Bentley et al., 1960). The persistence of high plasma FFA levels for 3 hours after transfusion was probably also due to heparin and is another argument in favour of ending the transfusion with an injection of protamine sulphate. Some authorities make no comment regarding protamine sulphate after exchange transfusion (Davies et al., 1972) and none was given in this study. The clinical significance of leaving the infant heparinized at the end of transfusion awaits further investigation but it is noteworthy that no baby in the present study gave concern because of haemorrhage or hyperbilirubinaemia after heparin transfusion.

The maintenance of plasma growth hormone 
levels in either type of transfusion resembled the findings with ACD transfusions (Milner and Wright, 1966) and the ACD transfusions (Milner et al., 1972a). The insignificant difference between ACD and heparin transfusions may be fortuitous, indicating that a heparin transfusion is less stressful than an ACD transfusion, or may be due to the stimulation of growth hormone secretion by glucose.

Two conclusions relating to clinical practice may be drawn from this study. If an infant is transfused with heparinized blood it is advisable to give protamine sulphate at the end of the procedure to counteract the anticoagulant action of heparin and to reduce the stimulation of FFA release by lipoprotein lipase. After either type of transfusion it is important to feed the baby as soon as practicable. This will reduce the risk of hypoglycaemia in infants transfused with ACD blood and will help FFA levels to fall in those who have been given heparinized blood. If feeding via the gastrointestinal tract is not possible, an intravenous glucose infusion should be considered.

We are grateful to Professor J. A. Davis for encouragement. This work was supported by the Medical Research Council and the British Diabetic Association. A.C. is the European Society for Clinical Investigation Research Fellow supported by the Wellcome Trust.

\section{REFERENCES}

Bentley, H. P., Jr., Ziegler, N. R., and Krivit, W. (1960). Use of heparinized blood for exchange transfusion in infants. American fournal of Diseases of Children, 99, 8.

Calladine, M., Gairdner, D., Naidoo, B. T., and Orrell, D. H. (1965). Acid-base changes following exchange transfusion with citrated blood. Archives of Disease in Childhood 40, 626.

Cser, A., and Milner, R. D. G. (1975). Metabolic and hormonal consequences of exchange transfusion via the umbilical artery or vein. Biology of the Neonate. (In the press.)

Davies, P. A., Robinson, R. J., Scopes, J. W., Tizard, J. P. M., and Wigglesworth, J. S. (1972). Medical Care of Newborn Babies, p. 153. Clinics in Developmental Medicine, 44/45. Heinemann, London.

Ehrlich, J., and Stivala, S. S. (1973). The chemistry and pharmacology of heparin. Journal of Pharmaceutical Sciences, 62, 517 .
Falorni, A., Fracassini, F., Massi-Benedetti, F., and Amici, A., (1972). Glucose metabolism, plasma insulin, and growth hormone secretion in newborn infants with erythroblastosis fetalis compared with normal newborns and those born to diabetic mothers. Pediatrics, 49, 682.

Farquhar, J. W., and Smith, H. (1958). Clinical and biochemical changes during exchange transfusion. Archives of Disease in Childhood, 33, 142.

Greville, G. D. (1943). The intravenous glucose tolerance equation. Biochemical fournal, 37, 17.

Isles, T. E., Dickson, M., and Farquhar, J. W. (1968). Glucose tolerance and plasma insulin in newborn infants of normal and diabetic mothers. Pediatric Research, 2, 198.

Milner, R. D. G., Chouksey, S. K., and Assan, R. (1973). Metabolic and hormonal effects of glucagon infusion in erythroblastotic infants. Archives of Disease in Childhood, 48, 885.

Milner, R. D. G., Fekete, M., and Assan, R. (1972a). Glucagon, insulin, and growth hormone response to exchange transfusion in premature and term infants. Archives of Disease in Childhood, $47,186$.

Milner, R. D. G., Fekete, M., Assan, R., and Hodge, J. S. (1972b). Effect of glucose on plasma glucagon, growth hormone, and insulin in exchange transfusion. Archives of Disease in Childhood, 47, 179.

Milner, R. D. G., and Wright, A. D. (1966). Blood glucose, plasma insulin and growth hormone response to hyperglycaemia in the newborn. Clinical Science, 31, 309.

Mølsted-Pedersen, L., Trautner, H., and Jørgensen, K. R. (1973). Plasma insulin and $\mathrm{K}$ values during intravenous glucose tolerance test in newborn infants with erythroblastosis foetalis. Acta Paediatrica Scandanavica, 62, 11 .

Odell, G. B. (1959). The dissociation of bilirubin from albumin and its clinical implications. Fournal of Pediatrics, 55, 268.

Polacek, K., Novak, M., and Melichar, V. (1965). Influence of free fatty acids on the distribution of bilirubin and its clinical significance in the newborn. Review of Czechoslovak Medicine, 11, 161.

Radde, I. C., Parkinson, D. K., Hoffken, B., Appiah, K. E., and Hanley, W. B. (1972). Calcium ion activity in the sick neonate: effect of bicarbonate administration and exchange transfusion. Pediatric Research, 6, 43.

Schiff, D., Aranda, J. V., Chan, G., Colle, E., and Stern, L. (1971a). Metabolic effects of exchange transfusions. I. Effect of citrated and of heparinized blood on glucose, non-esterified fatty acids, 2-(4 hydroxy-benzeneazo) benzoic acid binding and insulin. Journal of Pediatrics, 78, 603.

Schiff, D., Aranda, J. V., Colle, E., and Stern, L. (1971b). Metabolic effects of exchange transfusion. II. Delayed hypoglycemia following exchange transfusion with citrated blood. Fournal of Pediatrics, 79, 589.

Wiener A. S., and Wexler, I. B. (1946). The use of heparin when performing exchange blood transfusions in newborn infants. fournal of Laboratory and Clinical Medicine, 31, 1016.

Correspondence to Dr. R. D. G. Milner, Department of Child Health, St. Mary's Hospital, Whitworth Park, Manchester M13 0JH. 